\title{
PENGARUH CARA BELAJAR TERHADAP HASIL BELAJAR MATEMATIKA SMK JANUR PERSADA SIGI
}

\author{
Dewi Sri Wahyuni \\ Program Studi Pendidikan Matematika, FKIP, Universitas Alkhairaat \\ dewi031104016@gmail.com
}

\begin{abstract}
ABSTRAK
Penelitian ini bertujuan untuk mengetahui ada tidaknya pengaruh cara belajar siswa terhadap hasil belajar matematika. Selain itu, penelitian ini memiliki tujuan untuk mengetahui seberapa besar pengaruh cara belajar siswa terhadap hasil belajar matematika SMK JANUR PERSADA SIGI. Jenis Penelitian ini adalah penelitian Ex post Facto. Populasi dalam penelitian ini adalah seluruh siswa SMK JANUR PERSADA SIGI tahun ajaran 2018/2019. Berdasarkan data yang diperoleh dari sekolah bahwa jumlah siswa adalah 80 siswa yang terdiri, siswa kelas X sebanyak 25 siswa, kelas XI sebanyak 20 siswa dan kelas XII sebanyak 35 siswa. Adapun Sampel pada penelitian ini adalah seluruh siswa di SMK JANUR PERSADA SIGI.. Instrumen penelitian yang digunakan adalah angket cara belajar dan Tes Hasil Belajar Matematika. Analisis data hasil penelitian dilakukan dengan menggunakan program komputer SPSS versi 20.0. Hasil penelitian menunjukkan bahwa: (1) Sebagian besar siswa SMK JANUR PERSADA SIGI memiliki cara belajar berada pada kategori sedang dengan skor rata-rata 38,50 dengan standar deviasi 5,4321 dari skor minimum 14 sampai maximum 56; dan hasil belajar matematika pada kategori sangat rendah dengan skor rata-rata 29,31 dengan standar deviasi 7,833 dari skor minimum 0 sampai maximum 100. (2) Cara belajar SMK JANUR PERSADA SIGI berada pada kategori sedang. (3) Hasil belajar matematika siswa SMK JANUR PERSADA SIGI berada pada kategori sangat rendah. (4) besar pengaruh cara belajar siwa dengan hasil belajar matematika sebesar $51,1 \%$. Sedangkan $48,9 \%$ hasil belajar siswa dipengaruhi oleh variabel yang lain yang tidak diteliti.
\end{abstract}

Kata kunci: Cara belajar, hasil belajar matematika.

\begin{abstract}
This study aims to determine whether or not there is an influence of student learning styles on learning outcomes of mathematics. In addition, this study aims to determine how much influence students learning styles about the learning outcomes of mathematics in SMK JANUR PERSADA SIGI. This type of research is Expost Facto's research. The population in this study were all students of the SMK JANUR PERSADA SIGI, the number of students is 80 students consisting, students of class X as many as 25 students, class XI as many as 20 students and class XII as many as 35 students. The sample in this study was all students in the SMK JANUR PERSADA SIGI. The research instruments used were questionnaires on learning styles and Mathematics Learning Outcomes Test. Analysis of the results of the research data was carried out using the SPSS version 20.0 computer program. The results of the study show that: (1) Most students of the SMK JANUR PERSADA SIGI have learning styles in the moderate category with an average score of 38.50 with a standard deviation of 5.4321 from a minimum score of 14 to maximum 56; and mathematics learning outcomes in the very low category with an average score of 29.31 with a standard deviation of 7.833 from a minimum score of 0 to maximum 100. (2) The learning styles the SMK JANUR PERSADA SIGI is in the moderate category. (3) The mathematics learning outcomes of the SMK JANUR PERSADA SIGI are in the very low category. (4) the influence of The way to study with mathematics learning outcomes is $51.1 \%$. While $48.9 \%$ of student learning outcomes are influenced by other variables not examined.
\end{abstract}

Keywords: learning styles, mathematics learning outcomes 


\section{PENDAHULUAN}

Pada era globalisasi seperti sekarang ini, pendidikan memegang peranan yang sangat penting dalam kehidupan manusia untuk meningkatkan kualitas sumber daya manusia dalam hal pengetahuan dan keterampilan agar memiliki kemampuan berfikir kritis, kreatif, dan sikap terbuka. Masyarakat modern umumnya memandang pendidikan sebagai peranan penting dalam kehidupan. Pendidikan diharapkan dapat mengembangkan wawasan anak sehingga dapat membawa kemajuan individu, masyarakat dan negara untuk mencapai tujuan pembangunan nasional dalam mempersiapkan sumber daya manusia yang berkualitas di Indonesia, yang meliputi pembangunan manusia, baik sebagai insan maupun sebagai sumber daya pembangunan.

Nabi Muhammad Shalallahu Alaihi Wa salam bersabda : "Carilah ilmu sejak buaian hingga keliang lahat", berdasarkan hadist tersebut dapat dikatakan belajar merupakan proses yang dilakukan manusia sepanjang hayat, hal ini dikarenakan belajar sudah menjadi fitrah manusia itu sendiri. Dimana manusia belajar berdasarkan pengalaman yang ia miliki seperti yang dikemukaan oleh Cronbach bahwa "Learning is show by change in behavior as result of experience". Dari pengalaman yang diperoleh manusia tersebut manusia mendapatkan perubahan perilaku dalam memahami segala sesuatu yang terjadi, hal ini didukung oleh Morgan dan kawan-kawan (Baharuddin \& Wahyuni, 2015) yang mengatakan bahwa belajar adalah perubahan tingkah laku yang relatif tetap dan terjadi sebagai hasil latihan atau pengalaman.

Adapula yang mengemukakan pendapatnya bahwa belajar adalah seluruh rangkaian yang dilakukan seseorang secara sadar (mandiri atau berinteraksi dengan lingkungan/orang lain) yang mengakibatkan perubahan pada dirinya berupa penambahan pengetahuan dan keterampilan (jaeng, 2007). Hal ini menunjukan jika seorang manusia dikatakan belajar apabila melakukan kegiatan secara sadar yang akan mengakibatkan pengetahuan dan keterampilannya bertambah.
Perubahan tingkah laku pada manusia adalah hasil belajar dari pengalaman dan proses pembelajaran yang telah ia lalui. Sehingga hasil belajar merupakan hasil dari proses belajar. Bloom mengemukakan hasil belajar dibagi menjadi tiga ranah yaitu, kognitif, afektif, dan psikomotorik, dimana ranah kognitif berisi perilaku yang menekankan aspek intelektual seperti pengetahuan, dan keterampilan berfikir. Sedangkan ranah afektif berisi kemampuan yang berhubungan dengan sikap, nilai, minat dan apresiasi. Kemudian ranah psikomotorik berkaitan dengan keterampilan yang bersifat manual atau motorik.

Bloom membagi hasil bejar kognitif menjadi beberapa tipe yaitu (Sudjana, 2011): (1) Pengetahuan (knowledge), Pemahaman (comprehention), (3) Penerapan (application), (4) Analisis (analysis), dan (5) Evaluasi (evaluation). Sedangkan Menurut Kwarthwohl, Bloom dan Maisa (1973) ranah afektif diklasifikasikan menjadi 5 tingkatan yaitu: (1) penerimaan, (2) partisipasi, (3) penilaian, (4) organisasi dan (5) pembentkan pola hidup. Kemudian Simpon (Suprihatiningrum, 2012)mengklasifikasikan tingkat hasil belajar ranah psikomotor menjadi: Persepsi, kesiapan, gerakan terbimbing, gerakan yang terbiasa, gerakan yang kompleks, penyesuaian pada gerakan, kreativitas. Berdasarkan uraian diatas, dapat simpulkan bahwa hasil belajar adalah hasil yang didapatkan seseorang dari proses belajar, dimana hasil belajar yang dimaksud adalah tingkah laku.

Faktor - faktor pendukung yang sangat diperlukan adalah kesadaran diri bahawa antara pendidikan di sekolah, keluarga, dan masyarakat saling berkaitan. Dan salah satu pengukur keberhasilan dalam pendidikan ketika hasil belajar disekolah mereka meningkat, tetapi ini hanya salah satunya saja karena pencapaian hasil belajar dapat ditentukan oleh potensi bawaan individu dan karakteristik siswa itu sendiri. Faktor kepribadian menjadi sangat penting untuk dipertimbangkan sebagai potensi bawaan individu yang berpengaruh terhadap hasil belajar. Salah satu faktor yang sangat perlu diperhatikan dalam pembelajaran adalah cara belajar siswa. 
Cara belajar merupakan suatu cara seseorang melakukan kegiatan belajar seperti bagaimana cara mempersiapkan belajar, mengikuti pelajaran, aktivitas belajar mandiri, pola belajar dan cara menghadapi ujian. Oemar Hamalik mengemukakan bahwa cara belajar adalah "kegiatan-kegiatan yang dilakukan dalam mempelajari sesuatu, artinya kegiatan-kegiatan yang seharusnya dilakukan dalam situasi belajar tertentu. Dalam situasi tertentu diperlukan cara belajar tertentu pula". Gie (Maryati, 2013: 7) mengemukakan cara belajar adalah rangkaian kegiatan yang dilaksanakan dalam usaha belajarnya.

Menurut The Liang Gie (1984) cara belajar yang baik akan menyebabkan berhasilnya belajar, sebaliknya cara belajar yang buruk akan menyebabkan kurang berhasilnya atau gagalnya belajar (Mappeasse, 2009: 1). Kemudian Gie juga mengemukakkan bahwa cara belajar adalah rangkaian kegiatan yang dilaksanakan dalam usaha belajarnya (Maryati, 2013: 7). Sedangkan Slameto $(1995 ; 82)$ menyatakan bahwa cara belajar adalah kebiasaan belajar atau cara belajar yang mempengaruhi belajar meliputi antara lain mengulang bahan pelajaran, membaca dan membuat catatan, konsentrasi, mengerjakan tugas, cara mengatur waktu belajar. Dari beberapa defenisi di atas dapat disimpulkan bahwa cara belajar adalah suatu kegiatan yang dilakukan seorang dalam usaha belajarnya dengan cara tertentu yang merupakan kebiasaan dari orang tersebut.

Cara belajar yang baik adalah salah satu faktor yang dapat meningkatkan hasil belajar siswa, cara belajar akan memberikan ciri dalam aktivitas belajar yang dilakukan siswa yang pada gilirannya dapat mempengaruhi hasil belajar siswa untuk melakukan proses belajar, tentunya membutuhkan strategi agar fokus terhadap pelajaran. Baik itu belajar dalam kelas maupun belajar sendiri. Tanpa memiliki strategi dan cara belajar yang baik akan menimbulkan rasa jenuh dalam berpikir terutama menghadapi bagian-bagian yang sulit dimengerti dari mata pelajaran yang diajarkan. Banyak siswa tidak mendapatkan hasil yang baik dalam pelajarannya karena cara belajar yang kurang efisien, dan untuk mendapatkan cara belajar yang efektif perlu adanya bimbingan serta strategi belajar yang baik.

Berdasarkan pemaparan di atas, maka dapat diasumsikan bahwa cara belajar merupakan slah satu variabel yang dapat mempengaruhi hasil belajar siswa. Oleh karena itu penulis tertarik untuk melakukan penelitian mengenai pengaruh cara belajar terhadap hasil belajar matematika SMK JANUR PERSADA SIGI.

\section{METODE PENELITIAN}

\section{Jenis Penelitian}

Jenis penelitian ini menggunakan penelitian ex post facto yang bersifat kausalitas. Penelitian ex post facto disini untuk menerangkan adanya hubungan sebab akibat variabel dan menguji hipotesis yang telah dirumuskan sebelumnya antara cara belajar terhadap hasil belajar matematika siswa.

\section{Desain Penelitian}

Desain penelitian adalah keseluruhan dari perencanaan untuk menjawab pertanyaan penelitian dan mengantisipasi beberapa kesulitan yang mungkin timbul selama proses penelitian.

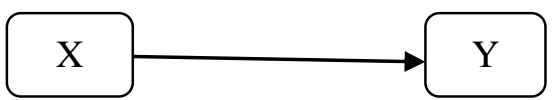

Gambar 1. Model Struktural Hubungan Antar Variabel

Keterangan:

$$
\begin{array}{ll}
\mathrm{X} & \text { : Cara Belajar } \\
\mathrm{Y} & \text { : Hasil Belajar Matematika. }
\end{array}
$$

\section{Populasi dan sampel}

Populasi dalam penelitian ini adalah seluruh siswa SMK JANUR PERSADA SIGI tahun ajaran 2018/2019. Berdasarkan data yang diperoleh dari sekolah bahwa jumlah siswa adalah 80 siswa yang terdiri, siswa 
kelas X sebanyak 25 siswa, kelas XI sebanyak 20 siswa dan kelas XII sebanyak 35 siswa. Adapun Sampel pada penelitian ini adalah seluruh siswa di SMK JANUR PERSADA SIGI.

\section{Instrumen Penelitian}

Pengumpulan data dilakukan dengan menggunakan instrumen yang berupa tes dan non tes. Tes dilakukan untuk memberikan informasi mengenai hasil belajar, sedangkan non tes dilakukan untuk memperoleh informasi mengenai cara belajar. Untuk mengukur variabel hasil belajar matematika siswa, maka pengumpulan data yang dilakukan adalah dengan menggunakan tes. Untuk mengukur cara belajar yaitu pengumpulan data yang dilakukan dengan menggunakan non tes dalam bentuk skala.
5. Kriteria pengklasifikasian skor variabel-variabel penelitian

Agar skor yang diperoleh dari setiap variabel dapat diinterpretasikan, maka harus diubah ke dalam bentuk nilai. Nilai tersebut berbentuk angka-angka kuantitatif maupun dalam bentuk kualitatif. Untuk mempermudah mendeskripsikan variabel penelitian digunakan kriteria tertentu yang mengacu pada skor rata-rata kategori skala yang diperoleh responden.

Variabel-variabel dikategorisasikan berdasarkan lima kategori skor yang dikembangkan dalam skala likert. Skor ditentukan melalui prosedur penskalaan yang akan menghasilkan angka-angka pada level pengukuran sebagai berikut (Azwar, 2013).

Tabel 1. Kategori penskoran

\begin{tabular}{cc}
\hline Skor & Kategori \\
\hline Skor terendah $\leq X<\mu-2,5(\sigma)$ & Sangat rendah \\
$\mu-2,5(\sigma) \leq X<\mu-1,5(\sigma)$ & Rendah \\
$\mu-1,5(\sigma) \leq X<\mu-0,5(\sigma)$ & Sedang \\
$\mu-0,5(\sigma) \leq X<\mu+0,5(\sigma)$ & Tinggi \\
$\mu+0,5(\sigma) \leq X<$ skor tertinggi & Sangat tinggi \\
\hline
\end{tabular}

Dimana, $\mu=$ skor terendah $\mathrm{x} 3$

$$
\sigma=\frac{\text { skor tertinggi-skor terendah }}{6}
$$

Selanjutnya untuk variabel hasil belajar didasarkan pada pengklasifikasian

departemen pendidikan (Kemendikbud, 2013), seperti pada Tabel 2.

Tabel 2. Kategori skor variabel hasil belajar matematika

\begin{tabular}{ll}
\hline $91 \%-100 \%$ & Sangat tinggi \\
$75 \%-90 \%$ & Tinggi \\
$60 \%-74 \%$ & Sedang \\
$40 \%-59 \%$ & Rendah \\
$0-39 \%$ & Sangat rendah \\
\hline
\end{tabular}

\section{Prosedur pengumpulan data}

Pengumpulan data dilakukan dengan memberikan instrumen kepada siswa yang merupakan sampel penelitian. Pengumpulan data ini akan dilakukan oleh peneliti. Pengumpulan data ini dilakukan bertahap sesuai dengan rencana dan jadwal penelitian sesuai dengan waktu yang telah disepakati antara peneliti dengan pihak sekolah. Pengumpulan data dilakukan dengan menggunakan instrumen yang berupa tes dan non tes (angket). Data yang diperoleh dari pemberian instrumen kepada siswa yang menjadi sampel penelitian ini digunakan untuk membantu dalam pengolahan analisis data untuk memperoleh suatu kesimpulan mengenai variabel-variabel dalam penelitian ini.

Hasil pengisian angket selanjutnya diskor melalui prosedur penskoran untuk merubah dari skala likert menjadi skala interval. Skor-skor akhir yang diperoleh 
inilah yang akan menjadi data penelitian untuk variabel-variabel kognitif yang diteliti.

\section{Teknik analisis data}

Data yang telah diperoleh dianalisis dengan menggunakan teknik analisis statistik, yaitu analisis statistik deskriptif dan inferensial.

Statistik deskriptif adalah statistik yang digunakan untuk menganalisis data dengan cara mendeskripsikan atau menggambarkan data yang telah terkumpul sebagaimana adanya, tanpa bermaksud membuat kesimpulan yang berlaku umum. Hal ini diperlukan untuk mendeskripsikan data dari variabel-variabel penelitian yang diajukan. Untuk teknik analisis deskriptif meliputi mean, median, variansi, skewness, kurtosis, minimum, maksimum, dan tabel distribusi frekuensi.

Statistika inferensial dimaksudkan untuk analisis dan validasi model yang diusulkan serta pengujian hipotesis. Oleh karena itu digunakan teknik analisis SEM dengan menggunakan paket program AMOS (Analysis Of Moment Structure) versi 20.0 dan SPSS versi 20.0

\section{HASIL DAN PEMBAHASAN}

\section{Cara Belajar}

Adapun distribusi frekuensi skor Cara Belajar siswa SMK JANUR PERSADA SIGI sebagai berikut:

Tabel 3. Distribusi skor cara belajar siswa

\begin{tabular}{ccccc}
\hline No & Skor & Frekuensi & Persentasi $(\%)$ & Kategori \\
\hline 1 & $14 \leq \mathrm{CB}<25$ & 3 & 3,8 & Sangat Rendah \\
2 & $25 \leq \mathrm{CB}<32$ & 9 & 11.2 & Rendah \\
3 & $32 \leq \mathrm{CB}<39$ & 23 & 28.6 & Sedang \\
4 & $39 \leq \mathrm{CB}<46$ & 31 & 38.8 & Tinggi \\
5 & $46 \leq \mathrm{CB} \leq 56$ & 14 & 17.6 & Sangat Tinggi \\
\hline \multicolumn{2}{c}{ Jumlah } & 80 & 100 & \\
\end{tabular}

Pada tabel diatas menunjukkan bahwa dapat diketahui bahwa 3 orang yang berada dalam kategori sangat rendah, 9 orang yang berada dalam kategori rendah, 23 orang yang berada dalam kategori sedang, 31 orang yang berada dalam kategori tinggi, dan 14 orang lainnya berada dalam kategori sangat tinggi. Sehingga dapat diartikan bahwa cara belajar berpengaruh cukup baik pada siswa SMK JANUR PERSADA SIGI

2. Hasil Belajar Matematika

Adapun distribusi frekuensi skor Hasil Belajar Matematika SMK JANUR PERSADA SIGI sebagai berikut:

Tabel 4. Distribusi skor tes hasil belajar matematika siswa

\begin{tabular}{lcccc}
\hline No & Skor & Frekuensi & Persentasi $(\%)$ & Kategori \\
\hline 1 & $0 \leq \mathrm{HB}<40$ & 31 & 38,8 & Sangat Rendah \\
2 & $40 \leq \mathrm{HB}<60$ & 21 & 26.2 & Rendah \\
3 & $60 \leq \mathrm{HB}<75$ & 15 & 18.8 & Sedang \\
4 & $75 \leq \mathrm{HB}<90$ & 9 & 11.2 & Tinggi \\
5 & $90 \leq \mathrm{HB} \leq 100$ & 4 & 5.0 & Sangat Tinggi \\
\hline & Jumlah & 80 & 100 & \\
\hline
\end{tabular}

Pada tabel 4 menunjukkan bahwa dapat diketahui bahwa 31 orang yang berada dalam kategori sangat rendah, 21 orang yang berada dalam kategori rendah, 15 orang yang berada dalam kategori sedang, 9 orang yang berada dalam kategori tinggi, dan 4 orang lainnya berada dalam kategori sangat tinggi, yang berarti Hasil Belajar matematika peserta didik terhadap berada dalam kategori sangat rendah.

3. Verifikasi model dan pengembangan model fit 
Model teoritis yang telah dikembangkan diverifikasi berdasarkan data empiris. Bagian ini dalam metode SEM merupakan bagian model struktural.

Tabel 5. Regresion weights untuk model tahap akhir

\begin{tabular}{|c|c|c|c|c|c|c|}
\hline & & & Estimate & S.E. & C.R. & $\mathbf{P}$ \\
\hline $\mathbf{Y}$ & $<--$ & $\mathrm{X}$ & .657 & .134 & 4.911 & $* * *$ \\
\hline
\end{tabular}

Tabel Regression Weights menunjukkan nilai estimasi pengaruh satu variabel terhadap variabel lainnya, serta probabilitas yang menunjukkan signifikansi
Hasil estimasi parameter (regression weight) disajikan dalam Tabel 5 berikut:

Tabel 6. Koefisien regresi terbakukan (standardized regression weights)

\begin{tabular}{llll}
\hline & & Estimate \\
\hline $\mathbf{Y}$ & $<---$ & $\mathrm{x}$ & .749 \\
\hline
\end{tabular}

Tabel 7. Squared multiple correlations

\begin{tabular}{ll}
\hline & Estimate \\
\hline $\mathbf{Y}$ & .511 \\
\hline
\end{tabular}

Berdasarkan Tabel 6 dan Tabel 7, maka diperoleh persamaan model struktural sebagai berikut:

$Y=0,749 X+\varepsilon_{1} ; \quad R_{Y}^{2}=51,1 \%$

Dimana: $\quad \mathrm{X}$ adalah cara belajar. Y adalah hasil belajar.

Persamaan struktural yang diperoleh melalui model tahap final diharapkan dapat menjelaskan kondisi keterhubungan antara cara belajar dan hasil belajar matematika siswa.

Persamaan regresi $\mathrm{Y}=0,749 \mathrm{X}+\varepsilon_{2}$ dan $R_{Y}^{2}=51,1 \%$, berarti bahwa sekitar $51,1 \%$ variansi hasil belajar siswa dapat dijelaskan oleh cara belajar siswa, sehingga masih ada 48,9\% varians hasil belajar dijelaskan oleh faktor-faktor lain yang tidak ikut diselidiki dalam penelitian ini. Faktorfaktor tersebut kemungkinan mengakibatkan belum maksimalnya hasil belajar matematika yang dicapai siswa.

Sehingga mendukung teori - teori yang menyatakan bahwa cara belajar atau kebiasaan belajar yang mempengaruhi belajar meliputi antara lain mengulang bahan pelajaran, membaca dan membuat catatan, konsentrasi, mengerjakan tugas, cara mengatur waktu belajar dapat mempengaruhi hasil belajar siswa. Sehingga benar jika Menurut The Liang Gie (1984) cara belajar yang baik akan menyebabkan berhasilnya belajar, sebaliknya cara belajar yang buruk akan menyebabkan kurang berhasilnya atau gagalnya belajar

\section{KESIMPULAN}

Berdasarkan hasil analisis data penelitian, beberapa kesimpulan dari hasil penelitian ini adalah: (1) Sebagian besar siswa SMK JANUR PERSADA SIGI memiliki cara belajar berada pada kategori sedang dengan skor rata-rata 38,50 dengan standar deviasi 5,4321 dari skor minimum 14 sampai maximum 56; dan hasil belajar matematika pada kategori sangat rendah dengan skor rata-rata 29,31 dengan standar deviasi 7,833 dari skor minimum 0 sampai maximum 100. (2) Cara belajar SMK JANUR PERSADA SIGI berada pada kategori sedang. (3) Hasil belajar matematika siswa SMK JANUR PERSADA SIGI berada pada kategori sangat rendah. (4) besar pengaruh cara belajar siwa dengan hasil belajar matematika sebesar $51,1 \%$. Sedangkan 48,9\% hasil belajar siswa 
dipengaruhi oleh variabel yang lain yang tidak diteliti.

\section{SARAN}

Beberapa saran yang berkaitan dengan penelitian ini, sebagai berikut: (1) Hasil penelitian ini dapat dijadikan informasi bagi siswa tentang faktor-faktor yang berpengaruh terhadap hasil belajarnya, sehingga siswa dapat mengembangkan faktor-faktor yang ada untuk memaksimalkan belajarnya., (2) Penelitian ini dapat diharapkan dapat menjadi masukan kepada Guru agar dalam suatu pembelajaran bukan hanya kemampuan kognitif siswa yang dilihat tetapi juga faktorfaktor psikologi siswa yang dapat mempengaruhi hasil belajar siswa., (3) Penelitian ini dapat diharapkan dapat menjadi masukan kepada orangtua agar dalam suatu pembelajaran bukan hanya kemampuan kognitif siswa yang dilihat tetapi juga faktorfaktor psikologi siswa yang dapat mempengaruhi hasil belajar siswa, dan (4) Bagi peneliti yang berminat untuk melakukan penelitian yang serupa, agar selain meneliti faktor-faktor internal yang mempengaruhi hasil belajar, juga dapan mengembangkan penelitian dengan meneliti faktor eksternal yang mempengaruhi hasil belajar. Peneliti juga dapat membandingkan faktor yang paling besar pengaruhnya terhadap hasil belajar siswa.

\section{DAFTAR PUSTAKA}

Tanpa tahun. Bimbingan Bagi Orang Tua Dalam Penerapan Pola Asuh Untuk Meningkatkan Kematangan Sosial Anak. (Online), (http://www.google.com/search?hl $=e n \& q=$ related: $w w w . d a m a n d i r i . o r$. id/file/muazarhabibiupibab2.pdf). Diakses tanggal 2 Maret 2019.

(2007). Membangkitkan Minat Belajar. (Online), (http://www.sumardiono. com/index.php?option=com_conte nt $\quad \&$ task=view \&id=735\&Itemid=79), diakses tanggal 2 Maret 2019.
(2007). Mengajar dan Belajar Berpikir Kreatif Melalui Matematika. Disertasi. (Online), (http://tatagyes.wordpress.com/abo ut/), diakses tanggal 2 Maret 2019.

. (2008). Konsep Diri, Perkembangan dan Pengaruhnya Terhadap Pencapaian Akademik Siswa, Serta Upaya Pembentukan Konsep Diri Berbasis Aktivitas Pembelajaran. (Online), (http://aikesari. multiply. com/journal/ item /28 / Konsep_ Diri_

Perkembangan_Dan_Pengaruhnya_ Terhadap_

Pencapaian_Akademik_Siswa_Sert a_Upaya

Pembentukan_Konsep_Diri_Berba sis_Aktivitas_Pembelajaran), diakses tanggal 2 Maret 2019.

. (2008). Jenis/Macam Tipe Pola Asuh Orangtua Pada Anak \& Cara Mendidik/Mengasuh Anak Yang Baik. (Online). (http://organisasi.org/jenis-macamtipe-pola-asuh-orangtua-pada-anakcara-mendidik-mengasuh-anakyang-baik), diakses 2 Maret 2019.

Enjang. (2009). Komunikasi Konseling. Bandung: Penerbit Nuansa

Gie, T. L.. (1995). Cara Belajar yang Efisien Jilid II. Yogyakarta: Liberty

Suprihatiningrum. J. (2013). Strategi Pembelajaran. Jogjakarta: Ar-ruzz Media

Slameto. (2003). Belajar dan Faktor - Faktor yang Mempengaruhinya. Jakarta : PT Rineka Cipta 